\section{A Flexible Function for Regressing Asymptotically Declining Responses of Plant Growth to Growth Retardants}

\author{
Osamu Kawabata and Joseph DeFrank \\ Department of Horticulture, University of Hawaii, Honolulu, HI 96822
}

Additional index words. modified power function, nonlinear regression, curve-fitting, statistics, growth inhibitors, purple nutsedge, Cyperus rotundus

\begin{abstract}
A modified power function, $y=(A+B \cdot x)^{-\mathrm{C}}$, was developed for determining the relationship between plant growth and growth retardant treatment. This function accounts for the plant response characteristics by incorporating three coefficients: A, growth level of the nontreated plants; $\mathrm{B}$, the degree of growth reduction; and $\mathrm{C}$, the smallest effective dose of the growth inhibitor. The function accounted for $97 \%$ of the variation in purple nutsedge (Cyperus rotundus $\mathrm{L}$.) leaf length as a function of the amount of a growth retardant applied. The procedure resulted in a smaller error sum of squares than several common nonlinear functions because of its greater shape flexibility.
\end{abstract}

Curve-fitting is an integral part of plant growth modeling (Hunt, 1982). Although linear regressions, such as polynomials, are commonly used, nonlinear regressions are desirable for responses that involve upper or lower bounds (Allen and Cady, 1982). Plant growth typically has an asymptotically declining response to growth retardants (e.g., Deyton et al., 1991): the plant response has a control value at zero inhibitor level and a lower bound (asymptote) at high dose levels. Three basic nonlinear functions are available for the inverse response: the exponential decay, the power, and the modified inverse functions (Spain, 1982). However, because these functions show different curve shapes, fitting all three functions is necessary to ensure the best fit. A flexible-shape function is desirable for fast and satisfactory curve-fittings of the asymptotic plant responses to growth retardants.

One approach to develop a flexible function is to assign a sufficient number of coefficients in a nonlinear function. Weibull (1951) and Richards (1959) each assigned four coefficients in their respective sigmoidal functions to represent as many desirable shape characteristics as they identified in the responses. Their functions fit sigmoidal responses better than three coefficient, fixed-shape sigmoidal functions, such as Gompertz and logistic (Brown and Mayer, 1988; Kawabata et al., 1984), because of the shape flexibility added by the extra coefficient. A flexible function for the asymptotically declining curve also can be developed in a similar manner.

Increasing the number of regression coefficients to be estimated raises computational requirements (e.g., time for programming and

Received for publication 14 Apr. 1994. Accepted for publication 21 July 1994. Hawaii Institute of Tropical Agriculture and Human Resources (HITAHR) Journal Series no. 3942. The cost of publishing this paper was defrayed in part by the payment of page charges. Under postal regulations, this paper therefore must be hereby marked advertisement solely to indicate this fact. computing) and trade-offs against improved curve fit (Landsberg, 1977). The noted functions incorporate only two coefficients, one for the intercept and one for the curvature, and the curves lack adequate flexibility. Therefore, the benefit of assigning more coefficients to improve the flexibility of curve may outweigh the need for the increased computational requirement. Our objective was to develop a function for the asymptotically declining responses that is more flexible than those mentioned, without raising the computational requirement.

\section{Materials and Methods}

Equation. Researchers generally are interested in three properties of plant response to growth retardants: 1) growth level of nontreated plants, 2) degree of growth reduction, and 3) smallest effective dose of the growth inhibitor. Each property can be identified as a shape characteristic in a regression curve: 1) an intercept on the y-axis, 2) a rapidly decreasing concave phase, and 3) an asymptotic phase in which y value slowly approaches the $\mathrm{x}$-axis. Therefore, a function is desirable in which these three characteristics are incorporated as coefficients in a simple mathematical form. We satisfied these requirements in the following modified power function (MPF) by adding a base modifier to the power function:

$y=(A+B \cdot x)^{-C}$

where $\mathrm{A}=$ an intercept factor, $\mathrm{B}=\mathrm{a}$ sharpnessof-bending factor, $\mathrm{C}=$ an asymptote factor, $\mathrm{x}=$ growth inhibitor concentration, and $\mathrm{y}=$ plant growth response.

The MPF coefficients have specific effects on the regression curve. The intercept factor (A) adjusts for the growth level of a nontreated plant (Fig. 1A). As A increases, the y-axis intercept decreases. The sharpness-of-bending factor (B) adjusts for the degree of growth reduction (Fig. 1B). As B increases, the curve bends more sharply. The asymptote factor (C) adjusts for the lowest effective dose of growth inhibitor (Fig. 1C). As $\mathrm{C}$ increases, the curve drops sharply to near zero at smaller doses of growth inhibitor.

The MPF is a nonlinear function in which coefficients depend on each other; therefore, unlike with linear functions, adjusting one shape characteristic causes other characteristics to shift. An iterative regression process is necessary to attain an optimal coefficient set that minimizes the error term (Allen and Cady, 1982).

Plant material. To demonstrate the MPF, growth retardation data were acquired for purple nutsedge by applying $\beta$-[(4-chlorophenyl) methyl]- $\alpha$-(1,1-dimethylethyl)- $1 H$-1,2,4triazole-1-ethanol (paclobutrazol). Purple nutsedge tubers and soil (very-fine, kaolinitic, isohyperthermic, Typic Haplustoll) were collected at the Waimanalo Expt. Station, Waimanalo, Hawaii. The soil was fumigated with $4.5 \mathrm{~g}$ methyl bromide/liter and transferred into 1-liter black plastic containers. Tubers (30) were individually planted $2 \mathrm{~cm}$ deep and drenched with paclobutrazol $(50 \%$ wettable powder) in 20-ml aqueous solution at

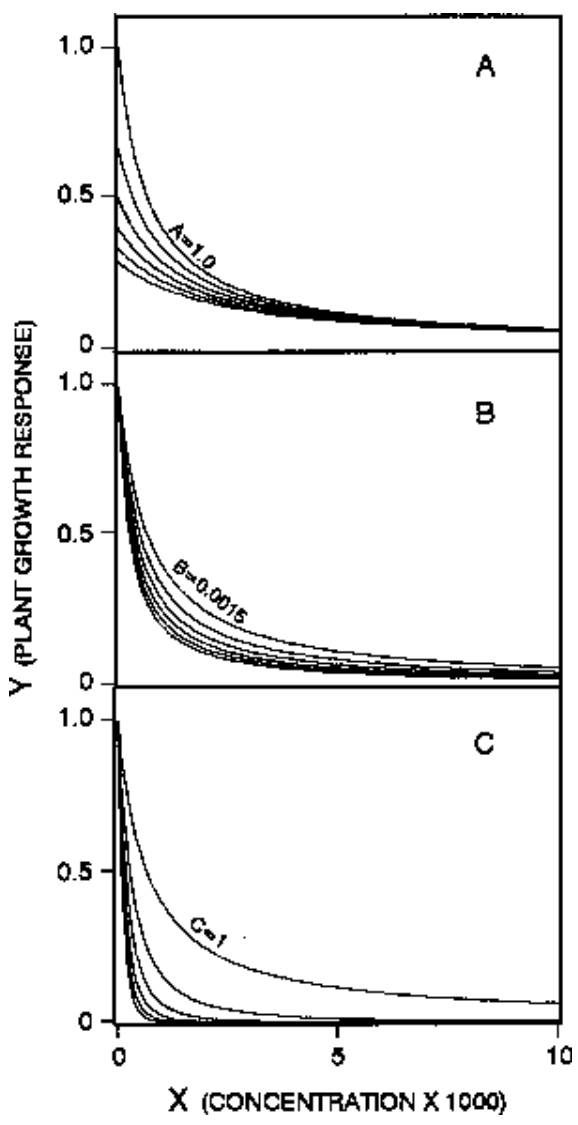

Fig. 1. Characteristics of coefficients in the modified power function: $y=(A+B \cdot x)^{-C}$. The coefficient $\mathrm{A}$ adjusts for $(\mathbf{A})$ the $y$-intercept $(\mathrm{A}=1.0$, 1.5, 2.0, 2.5, 3.0, and 3.5); (B) the coefficient B for the sharpness of bending $(\mathrm{B}=0.0015,0.0020$, $0.0025,0.0030,0.0035$, and 0.0040); and (C) the coefficient $\mathrm{C}$ for the beginning of the inhibitory growth regulator concentration $(\mathrm{C}=$ $1,2,3,4,5$, and 6). Other coefficients were kept constant at 1.0, 0.0015, and 1 for A to $\mathrm{C}$, respectively. 
$0,0.5,2,8$, or $32 \mathrm{mg}$ a.i./liter soil, followed by an additional $80-\mathrm{ml}$, water-incorporation drench. The range of paclobutrazol concentrations was based on a previous report (Kawabata and DeFrank, 1993). Each container received $0.55 \mathrm{~g}$, slow-release, $18 \mathrm{~N}-2.6 \mathrm{P}-9.9 \mathrm{~K}$ fertilizer and $20 \mathrm{mg}$ minor elements (Micromax, Grace Sierra Chemicals, Milpitas, Calif.). Containers were placed on outdoor benches and watered twice daily. The longest leaf produced by each plant was measured 33 days after tuber planting. Each treatment was replicated 6 times.

Purple nutsedge leaf length was regressed against paclobutrazol concentration using the MPF, the exponential decay, the power, and the modified inverse functions. For each function, coefficient values were initially set by a grid search (Sall, 1981) and iteratively optimized by the SAS nonlinear regression procedure with the "doesn't-use-derivative" option (SAS Institute, 1990). The deviation between treatment mean and the expected value (error) and the error sum of squares (ESS) were computed to measure the accuracy of estimates. Because exponential functions are commonly added to linear coefficients (LC) to adjust for the lower asymptote (Bates and Watts, 1988), an additional set of regressions was performed using the functions added to LC. The regression curves and treatment means were plotted together to evaluate fit graphically.

\section{Results and Discussion}

Adding LC to the exponential decay, the power, and the modified inverse functions (three-coefficient functions) reduced the ESS by $79 \%, 83 \%$, and $85 \%$, respectively, as asymptotes were freed from the $\mathrm{x}$-axis (Table 1). In contrast, the ESS reduction was only $12 \%$ for the MPF because the coefficient $C$ adjusted for the lower asymptote, Eq. [1]. Despite the large ESS reduction for the common inverse functions by the LC, the MPF resulted in the smallest ESS with or without the LC. We felt that the small improvement in the fit of the MPF by adding LC did not justify the increase in complexity that it added to the regression. The MPF without LC accounted for $97 \%$ of the corrected total sum of squares.

The MPF was the most reliable function in the entire inhibitor range; its errors were small and of similar magnitude for all paclobutrazol concentrations (Table 2). Although all of the MPF estimates were within the $90 \%$ confidence interval of the actual means, other functions estimated the actual means outside the confidence interval for at least one paclobutrazol concentration.

The MPF displayed superior shape flexibility (Fig. 2). It satisfied all three desirable shape characteristics, a correct intercept, a sharpness of bending, and an asymptotic phase. In contrast, the exponential decay and the power functions had less satisfactory curve bending than the MPF, and the modified inverse function fit poorly in the asymptotic phase (at the 8- and 32-mg treatments). The greater flexibility of the MPF was due to having two coefficients (B and C) for forming curves, compared to one for the other functions. Because all functions in Fig. 2 contained three coefficients, comparing the model fit based on the smallest ESS was valid. The MPF was demonstrated as the most flexible, and it required no more computational resources than other functions.

Table 1. The comparison of error sum of squares (ESS) for purple nutsedge leaf length estimated by four asymptotic functions. The growth retardation was caused by soil-applied paclobutrazol; leaf length was measured 33 days after tuber planting.

\begin{tabular}{|c|c|c|c|c|}
\hline Function & $\begin{array}{c}\text { Exponential } \\
\text { decay } \\
\text { function } \\
\mathrm{y}=\mathrm{A} \cdot \mathrm{e}^{\mathrm{Bx}}\end{array}$ & $\begin{array}{l}\text { Power } \\
\text { function } \\
\mathrm{y}=\mathrm{A} \cdot \mathrm{x}^{\mathrm{B}}\end{array}$ & $\begin{array}{l}\text { Modified } \\
\text { inverse } \\
\text { function } \\
\mathrm{y}=\mathrm{A} /(\mathrm{B}+\mathrm{x})\end{array}$ & $\begin{array}{c}\text { Modified } \\
\text { power } \\
\text { function } \\
\mathrm{y}=(\mathrm{A}+\mathrm{B} \cdot \mathrm{x})^{-\mathrm{C}}\end{array}$ \\
\hline$\overline{\mathrm{ESS}^{\mathrm{z}}}$ & 15280 & 5810 & 4841 & 130 \\
\hline ESS with LC $^{y}$ & 3209 & 975 & 718 & 115 \\
\hline Percent ESS reduction & 79 & 83 & 85 & 12 \\
\hline
\end{tabular}

${ }^{2}$ Error sum of squares $=$ sum of squares of deviation between means and expected values.

${ }^{y} \mathrm{LC}=$ linear coefficient, added to the nonlinear functions to adjust for the lower asymptote level.

Table 2. The comparison of errors for purple nutsedge leaf length estimated by four asymptotic functions. The growth retardation was caused by soil-applied paclobutrazol; leaf length was measured 33 days after tuber planting.

\begin{tabular}{|c|c|c|c|c|c|}
\hline \multirow[b]{2}{*}{$\begin{array}{l}\text { Paclo- } \\
\text { butrazol } \\
\text { (mg a.i./ } \\
\text { liter) }\end{array}$} & \multirow[b]{2}{*}{$\begin{array}{c}\text { Leaf } \\
\text { length } \\
\text { mean } \\
\pm 90 \% \mathrm{CI}^{\mathrm{y}} \\
(\mathrm{mm}) \\
\end{array}$} & \multicolumn{4}{|c|}{ Error (expected value - treatment mean) } \\
\hline & & $\begin{array}{c}\text { Exponential } \\
\text { decay } \\
\text { function }^{\mathrm{z}} \\
\mathrm{y}=\underset{(\mathrm{mm})}{\mathrm{LC}+\mathrm{A} \cdot \mathrm{e}^{\mathrm{Bx}}}\end{array}$ & $\begin{array}{c}\text { Power } \\
\text { function } \\
\mathrm{y}=\underset{\mathrm{LC}+\mathrm{A} \cdot \mathrm{x}^{\mathrm{B}}}{(\mathrm{mm})}\end{array}$ & $\begin{array}{c}\text { Modified } \\
\text { inverse } \\
\text { function } \\
\mathrm{y}=\mathrm{LC}+\mathrm{A} /(\mathrm{B}+\mathrm{x}) \\
(\mathrm{mm})\end{array}$ & $\begin{array}{c}\text { Modified } \\
\text { power } \\
\text { function } \\
\mathrm{y}=\left(\begin{array}{c}\mathrm{A}+\mathrm{B} \cdot \mathrm{x})^{-\mathrm{C}} \\
(\mathrm{mm})\end{array}\right.\end{array}$ \\
\hline$\overline{0}$ & $175.3 \pm 6.4$ & -5.2 & -0.2 & -1.1 & 0.1 \\
\hline 0.5 & $109.7 \pm 9.6$ & 10.9 & -11.7 & 3.7 & -1.1 \\
\hline 2 & $67.2 \pm 5.8$ & -10.6 & 3.8 & -2.6 & 2.8 \\
\hline 8 & $44.0 \pm 6.3$ & -9.1 & 0.2 & -7.0 & -2.9 \\
\hline 32 & $20.8 \pm 12.8$ & 14.0 & -3.3 & 7.0 & 1.1 \\
\hline
\end{tabular}

${ }^{2}$ Leaf length (y, millimeter) is regressed against paclobutrazol applied (x, milligram a.i. per liter): $y=34.80$ $+135.34 \cdot \mathrm{e}^{-0.9126 \mathrm{x}}$ (exponential decay function), $\mathrm{y}=-4041.68+4126.13 \cdot \mathrm{x}^{-0.004720}$ (power function), $\mathrm{y}=24.47$ $+109.42 /(0.7305+\mathrm{x})($ modified inverse function $)$, and $\mathrm{y}=(0.000003321+0.00001447 \cdot \mathrm{x})^{-0.4096}($ modified power function).

y Mean and confidence intervals $(\mathrm{CI})$ of six replications.

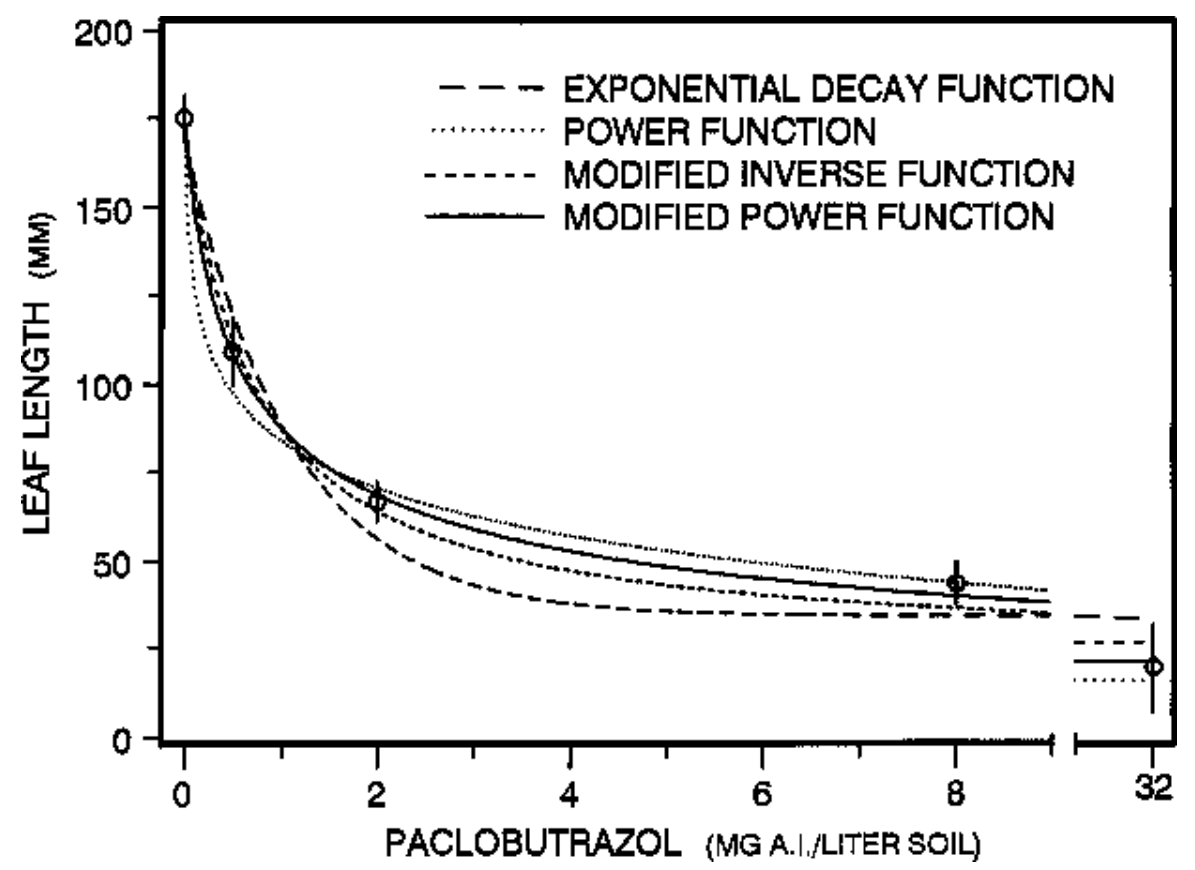

Fig. 2. Comparison of curves estimated by four asymptotic functions. The growth retardation was caused by soil-applied paclobutrazol; leaf length was measured 33 day after tuber planting. Circles and vertical bars represent mean leaf lengths and $90 \%$ confidence intervals, respectively. 
common asymptotic functions for plant growth modeling and statistical data analysis.

\section{Literature Cited}

Allen, D.M. and F.B. Cady. 1982. Nonlinear models, p. 294-309. In: Analyzing experimental data by regression. Lifetime Learning, Belmont, Calif.

Bates, D.M. and D.G. Watts. 1988. Nonlinear regression analysis and its applications. Wiley, New York.

Brown, R.F. and D.G. Mayer. 1988. Representing cumulative germination. 2. The use of the Weibull function and other empirically derived curves. Ann. Bot. 61(2):127-138.

Deyton, D.E., C.E. Sams, and J.C. Cummins. 1991. Strawberry growth and photosynthetic responses to paclobutrazol. HortScience 26:1178-1180.

Hunt, R. 1982. Plant growth curves: The functional approach to plant growth analysis. Univ. Park Press, Baltimore.

Kawabata, O., R.A. Criley, and S.R. Oshiro. 1984. Effects of season and environment on flowering of bird of paradise in Hawaii. J. Amer. Soc. Hort. Sci. 109:706-712.

Kawabata, O. and J. DeFrank. 1993. Purple nutsedge suppression with soil-applied paclobutrazol. HortScience 28:59.
Landsberg, J.J. 1977. Some useful equations for biological studies. Expt. Agr. 13(3):273-286.

Richards, F.J. 1959. A flexible growth function for empirical use. J. Expt. Bot. 10:290-300.

Sall, J. 1981. SAS regression applications. SAS Tech. Rpt. A-102. SAS Institute, Cary, N.C.

SAS Institute. 1990. SAS/STAT user's guide. 4th ed. Version 6. SAS Institute, Cary, N.C.

Spain, J. D. 1982. Fitting model equations to experimental data, p. 43-62. In: BASIC microcomputer models in biology. Addison-Wesley, Reading, Mass.

Weibull, W. 1951. A statistical distribution function of wide applicability. J. Applied Mechanics 18:293-297. 